\title{
Cadernode Pesquisa
}

Https://online.unisc.br/seer/index.php/cadpesquisa

ISSN on-line: $1677-5600$

Doi: $10.17058 /$ cp.v30i2.6884

Universidade de Santa cruz do Sul - Unisc

Recebido em 20 de Dezembro de 2015 Aceito em 16 de Outubro de 2018 Autor para contato: daniel.carvalho@ueg.br

\section{Trichoderma harzianum no tratamento de sementes de Cladosporium herbarum, Sclerotinia sclerotiorum e no aumento de crescimento do feijoeiro no Brasil}

\author{
Employment of Trichoderma to control Cladosporium sp. and Sclerotinia sclerotiorum and \\ bean growth promoting in Brazil
}

Gesiane Ribeiro Guimarães

Fabíola Teodoro Pereira

Universidade Estadual de Goiás - UEG - Ipameri - Goiás - Brasil

Sueli Corrêa Marques de Mello

Embrapa Recursos Genéticos e Biotecnologia - Brasília - Distrito Federal - Brasil

Daniel Diego Costa Carvalho

Universidade Estadual de Goiás - UEG - Ipameri - Goiás - Brasil

\section{Resumo}

O potencial de uso de Trichoderma spp. para o controle biológico de patógenos em sementes, assim como no controle de doenças do feijoeiro em condições de campo, tem sido constatado. Além de possuir diferentes mecanismos de antagonismo, tais como antibiose, competição e hiperparasitismo, possui habilidade para colonizar a rizosfera e as radículas das plântulas, podendo atuar no aumento da velocidade de crescimento inicial do feijoeiro. Esta revisão tem por finalidade levantar as recentes pesquisas realizadas no Brasil, acerca deste fungo como agente de biocontrole de Cladosporium sp., importante patógeno de sementes, e de Sclerotinia sclerotiorum causador do mofo branco, abordando seu efeito promotor no crescimento do feijoeiro.

\section{Abstract}

The use of Trichoderma has been evaluated for the biological control of pathogens on seeds, as well as in the control of common bean diseases, under field conditions. Besides having different mechanisms of control, such as antibiosis, competition and hyperparasitism, the fungus Trichoderma has the ability for colonizing the rhizosphere and the seedlings rootlets, acting also in the common bean early growth promotion. This review has as objective to survey the recent researches carried out in Brazil, about this fungus in the control of Cladosporium sp., an important seed pathogen, Sclerotinia sclerotiorum, causal agent of the white mold, and in the common bean growth promotion.

\section{Palavras-chave}

Aplicação foliar. Produtividade. Patologia de sementes. Phaseolus vulgaris. Crescimento.

\section{Keywords}

Foliar application. Grain yield. Phaseolus vulgaris. Seeds pathology. Growth. 


\section{Introdução}

O feijão consiste em uma importante fonte de proteínas na alimentação humana dos países em desenvolvimento das regiões tropicais e subtropicais (Alwathnani et al., 2012). No Brasil, o feijão é um dos componentes básicos da dieta alimentar da população e importante fonte de proteína (Barbosa e Gonzaga, 2012). Estima-se que a produção total de feijão no Brasil, na safra de 2013/2014 tenha sido de 2.899,1 toneladas (CONAB, 2014). O fungo Cladosporium sp. (Pers.) Link está associado com sementes de feijão durante o armazenamento e é capaz de provocar danos na germinação e no vigor, especialmente de sementes não tratadas (Guimarães et al., 2014). Já em relação a Sclerotinia sclerotiorum (Lib.) de Bary, causador do mofo branco, este fungo é exemplo de patógeno de maior ocorrência, causador de danos expressivos à cultura do feijoeiro, acarretando grandes prejuízos aos produtores brasileiros (Barbosa e Gonzaga, 2012).

Os agrotóxicos, a exemplo dos fungicidas, têm contribuído para ganhos na obtenção dos alimentos e das fibras necessárias à população mundial. Porém, estão relacionados ao aumento dos custos da produção, contaminação de alimentos e do meio ambiente e à crescente resistência dos microrganismos fitopatogênicos aos produtos sintéticos (Wutzki et al., 2016).

Nesse contexto, existe uma crescente valorização dos produtos da natureza, considerados confiáveis e seguros. As grandes companhias, visando a atender um mercado consumidor cada vez mais exigente, vêm procurando novas moléculas detentoras de atividade biológica e, com esse objetivo, examinando os elementos que constituem a biodiversidade, como plantas e microrganismos (Ferreira et al., 1998).

O Brasil é o país detentor da biodiversidade mais rica do mundo, porém não tem a mesma disponibilidade financeira para a realização de investimentos na área em questão (Moreira et al., 2004). Os microrganismos antagônicos, quando empregados como alternativa ao controle químico, podem proporcionar excelentes níveis de controle a médio e longo prazo, principalmente se a aplicação for simultânea ao controle genético de doenças de plantas ou dentro de um sistema de manejo integrado (Melo et al., 2006; Mello, 2014). Esta revisão tem por objetivo levantar e discutir as recentes pesquisas realizadas no Brasil com o fungo Trichoderma spp. no controle de Cladosporium sp. em sementes de feijão, no controle de $S$. sclerotiorum e na promoção do crescimento do feijoeiro.

\section{Desenvolvimento}

\section{O fungo Trichoderma no controle de fitopatógenos: aspectos relevantes}

Segundo Wood \& Tveit (1955), organismos selecionados como antagonistas não devem ser fitopatogênicos, devem ter propriedades que facilitem a aplicação na superfície das plantas/sementes ou solos e ter capacidade de rápido estabelecimento. Seus esporos ou estruturas de sobrevivência precisam germinar bem e rapidamente. Os organismos devem apresentar alta taxa de crescimento e capacidade reprodutiva, especialmente de esporos relativamente resistentes. Os antagonistas devem ser facilmente cultivados em meios disponíveis e não ser exigentes em seus requerimentos nutricionais, de modo que grandes quantidades de inóculos possam ser facilmente preparadas a baixo custo. Uma característica recomendável, mas não indispensável, é que o antagonista atue através de mais de um mecanismo, combinando de qualquer forma: antibiose, parasitismo, competição ou mesmo o estimulo à defesa do hospedeiro (Fravel, 2005; Machado et al., 2012). Como a integração dos métodos de controle tem se mostrado como a forma mais adequada de resolver os problemas fitopatológicos, sempre que a seleção de agentes de biocontrole tiver por objetivo o uso nesse 
sistema de manejo, é interessante que os antagonistas selecionados apresentem resistência aos fungicidas utilizados nas culturas (Fravel, 2005).

Tendo em vista as características desejáveis descritas no parágrafo anterior, fungos do gênero Trichoderma (reino Fungi, filo Ascomycota, classe Pyrenomycetes, ordem Hypocreales) estão entre os mais pesquisados como agentes de biocontrole. Esses fungos são de vida livre, encontrados nos mais diversos tipos de solo, especialmente nos solos orgânicos e capazes de parasitar outros fungos, atuam por diferentes mecanismos de controle biológico, como a antibiose, competição e parasitismo. Possuem capacidade de degradar diversos materiais e lisar parede de células de fungos (Machado et al., 2012) alimentando-se do conteúdo celular e, assim, colonizam rapidamente o substrato. Mais de um dos mecanismos anteriormente citados pode ser utilizado simultaneamente no processo antagonista (Consolo et al., 2012).

A literatura é rica em relatos de trabalhos realizados, no Brasil e no exterior, com sucesso no uso agrícola de Trichoderma, além de colonizar a rizosfera, as espécies desse fungo ( $T$. harzianum, T. koningiopsis, T. asperellum, T. virens, T. longibrachiatum, T. viridescens, $T$. brevicompactum) podem produzir substâncias promotoras do crescimento das plantas (HoyosCarvajal et al., 2009).

Uma sequência lógica à seleção de antagonistas para controle biológico procede através de vários estágios, e em teoria é de in vitro (testes em placas de Petri) para in vivo (testes em casa de vegetação e sob condições de campo). Andrews (1985) sugere preliminarmente seleção coordenada por uma das técnicas in vitro, em condições controladas, seguindo, posteriormente, para estádio definitivo que são os ensaios de campo. Assim, todos os métodos de seleção de antagonistas são baseados em evidências de que o organismo candidato interfere, de algum modo, no desenvolvimento do patógeno ou reduz a doença. Interferência implica em algumas formas de destruição ou inibição, podendo ser avaliada tanto in vitro como in vivo (Andrews, 1985). Para os testes in vitro, são utilizados os métodos de cultivo em placas de Petri com meio agarizado (Kishore et al., 2005). Também é importante mencionar que, se a principal meta da seleção de microrganismos antagônicos for encontrar produtores de antibióticos, especialmente para o controle de patógenos em sementes, os testes que demonstram antibiose in vitro são fundamentais (Carvalho et al., 2014). A seguir serão discutidos os principais trabalhos realizados no Brasil, onde empregaram-se isolados de Trichoderma spp. para o controle de Cladosporium sp. e S. sclerotiorum.

Trichoderma harzianum no controle de Cladosporium herbarum sp. em sementes de feijão. Os fungos que danificam órgãos de reserva, são considerados iniciadores da deterioração das sementes contando ou não com a colaboração de alguns fatores, como pequenas aberturas nas superfícies das sementes causadas por algumas espécies de insetos e choques mecânicos resultantes da colheita, transporte e armazenamento. Esses fatores somados às condições de umidade e temperatura promovem o desenvolvimento do microorganismo (Ito et al., 2003). O gênero Cladosporium, por sua vez, é comum em sementes de feijão durante o armazenamento e podem causar prejuízos na germinação e no vigor, quando as sementes não são adequadamente tratadas (Ito et al., 2003; Zucchi e Melo, 2009). O fungo C. herbarum pode causar manchas no tegumento, resultando em um aspecto indesejável e consequente depreciação dos lotes de sementes (Guimarães e Carvalho, 2014).

$\mathrm{O}$ uso de sementes tratadas com fungicidas sintéticos e/ou agentes de biocontrole ocasiona redução da dispersão de patógenos para áreas indenes e reduz a disseminação de patógenos no campo, contribuindo para maior densidade de plantas (Pereira et al., 2013). Para exemplificar essa evidência, pode-se citar o trabalho de Guimarães et al., (2014), onde o tratamento de sementes com suspensão de conídios de $T$. harzianum proporcionaram de 67 a $77 \%$ de controle de $C$. herbarum em sementes de feijão 'Pérola'. Poucos são os trabalhos abordando o controle biológico de Cladosporium em sementes no Brasil, de modo que, outro trabalho relevante é o de Carvalho et al., (2011). Estes autores trataram sementes de feijão 'Jalo Precoce' com o produto comercial Ecotrich ${ }^{\circ}$ SC (isolado comercial de T. harzianum, produzido pela Ballagro Agro Tecnologia Ltda., Atibaia, SP, Brasil) e obtiveram redução de $67 \%$ 
de incidência de Cladosporium sp. nas sementes. Esta redução ocorre porque o fungo Trichoderma compete com fungos fitopatogênicos pelos exsudatos liberados pelas sementes durante o processo de germinação (Harman et al., 2004). Além disso, a produção de metabólitos voláteis está mais relacionada ao biocontrole em sementes do que a produção de metabólitos não voláteis (Agüero et al., 2008; Carvalho et al., 2014) e, de modo geral, o fungo Trichoderma possui habilidade em ocupar agressivamente os sítios de estabelecimento do patógeno nas sementes e plântulas (Figura 1), propriedade considerada responsável pelo biocontrole de patógenos em sementes de feijão contaminadas (Carvalho et al., 2014).

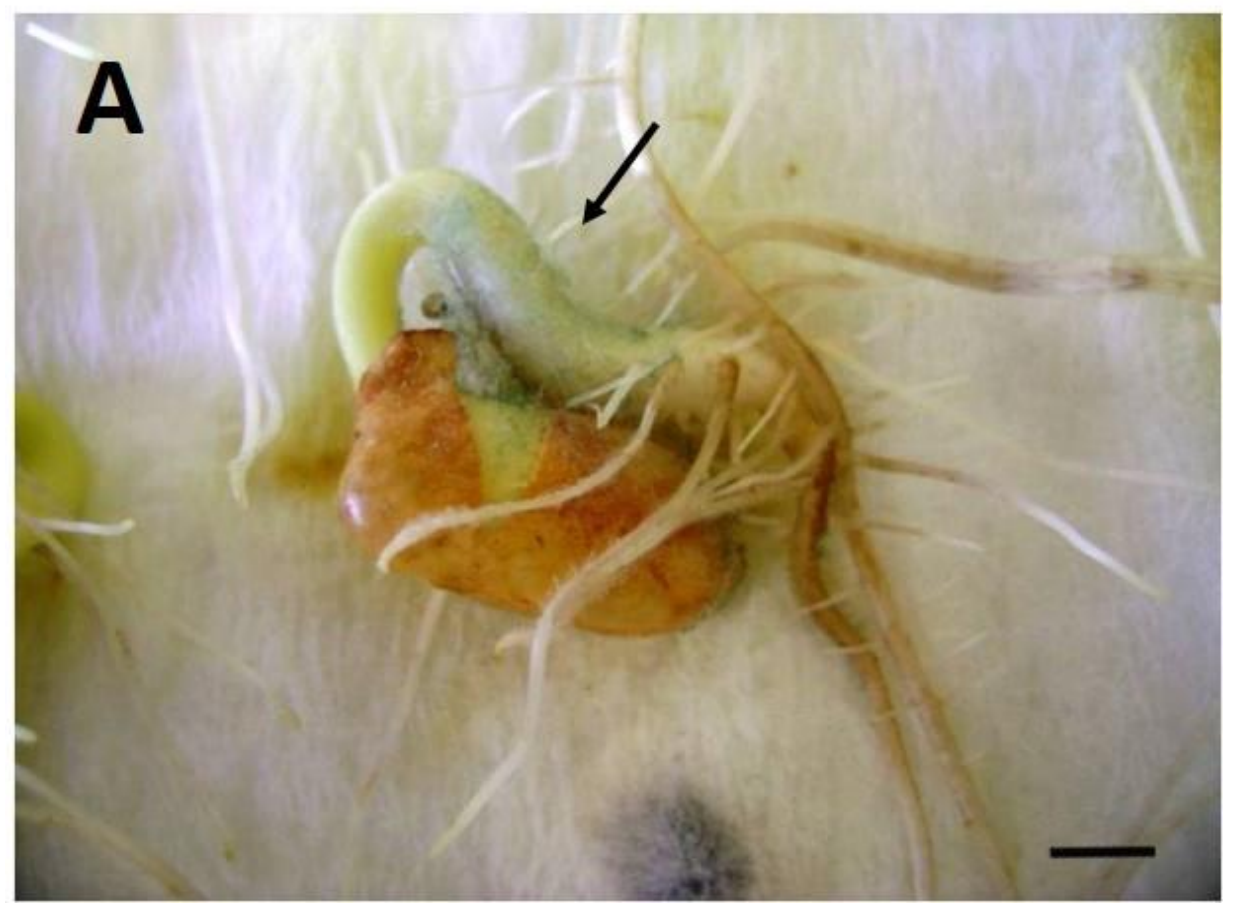

Figura 1 - (A) Seta exibindo região do hipocótilo de plântula de feijoeiro 'Jalo Precoce' colonizado por Trichoderma harzianum (isolado CEN287), após tratamento das sementes com suspensão de conídios do fungo ( $2.5 \times 10^{8}$ conídio $\mathrm{mL}^{-1}$ ) (Barra corresponde a 4,0 mm). FONTE: Daniel Diego Costa Carvalho.

\section{Trichoderma no controle do mofo branco do feijoeiro}

O mofo branco causado pelo fungo Sclerotinia sclerotiorum (Lib.) de Bary, é uma doença bastante difundida nas regiões produtoras de feijão, principalmente no plantio do outonoinverno. As perdas no rendimento atingem em média $50 \%$ podendo ser mais elevada (Lobo Junior et al., 2009). Com a introdução da terceira época de plantio na região Centro-Oeste e outras regiões do país, implicando no uso da irrigação por aspersão, o patógeno encontrou condições favoráveis para seu desenvolvimento, tornando-se um problema para os produtores desta leguminosa. Os sintomas iniciais são lesões encharcadas que se espalham rapidamente para as hastes, ramos e vagens. Nos tecidos infectados, aparece um micélio que lembra algodão, constituindo os sintomas característicos da doença (Bianchini et al., 2005). Na ausência de hospedeiro suscetível, a persistência dos escleródios no solo pode se estender por longos períodos (Vida et al., 2004)

Como etapa de um programa de controle biológico de $S$. sclerotiorum, muitos são os trabalhos publicados no Brasil, visando ao controle in vitro do patógeno (Louzada et al., 2009; Rocha et al., 2009; Lopes et al., 2012). Embora excelentes resultados de antagonismo a fitopatógenos possam ser observados em condições in vitro, tal sucesso não é, em muitos casos, verificado em condições de campo. Isso se deve às condições críticas de desenvolvimento no solo para organismos biológicos, uma vez que estes estão sujeitos às 
reações diferenciais do hospedeiro e ambiente, levando a eficácia de controle mais variável do que a obtida com fungicidas químicos (Harman, 1991). Neste contexto, trabalhos em que isolados são avaliados em casa de vegetação ou sob condições de campo possuem grande valor, principalmente quando os ensaios são conduzidos em meio a outros componentes (tipos de manejo adotado, técnica de aplicação, diferentes épocas do ano). Um ponto forte do controle biológico com Trichoderma consiste em aliá-lo a outros métodos de controle de doenças, como uso de cultivares resistentes, controle físico e cultural, melhorando a implementação do controle biológico no manejo integrado de doenças, ocupando espaços onde outras técnicas não são eficientes (Pereira et al., 2013). Interessantemente, o fungo Trichoderma tem mostrado melhor atuação contra patógenos habitantes do solo e menos especializados como, por exemplo, Sclerotium rolfsii,, Rhizoctonia sp. e Sclerotinia, pois, como também é um fungo habitante do solo, suas características de antagonismo são melhor expressas neste ambiente, pois estes fungos causam doenças em plantas (Huang et al., 2000; Saito et al., 2009).

Como já foi dito, na cultura do feijoeiro, existem diversos patógenos de importância epidemiológica que causam prejuízos à qualidade das sementes, dentre os quais, $S$. sclerotiorum. Este patógeno pode sobreviver em sementes por mais de três anos e, através delas, estabelecer a doença em novas áreas no início do ciclo da cultura (Souza et al., 2013), infecta as plântulas danificando o hipocótilo (Regras para análise de sementes, 2009). Assim, existem trabalhos no Brasil, visando ao controle biológico deste patógeno e nas sementes contaminadas (Fialho et al., 2011). Para exemplificar a importância desta linha de pesquisa, pode-se citar o trabalho de Carvalho et al., (2011), que reportaram isolados de T. harzinaum estatisticamente similares ao tratamento químico (Carboxin+Thiram), reduzindo em $92 \%$ a incidência de $S$. sclerotiorum nas sementes (Figura 2).
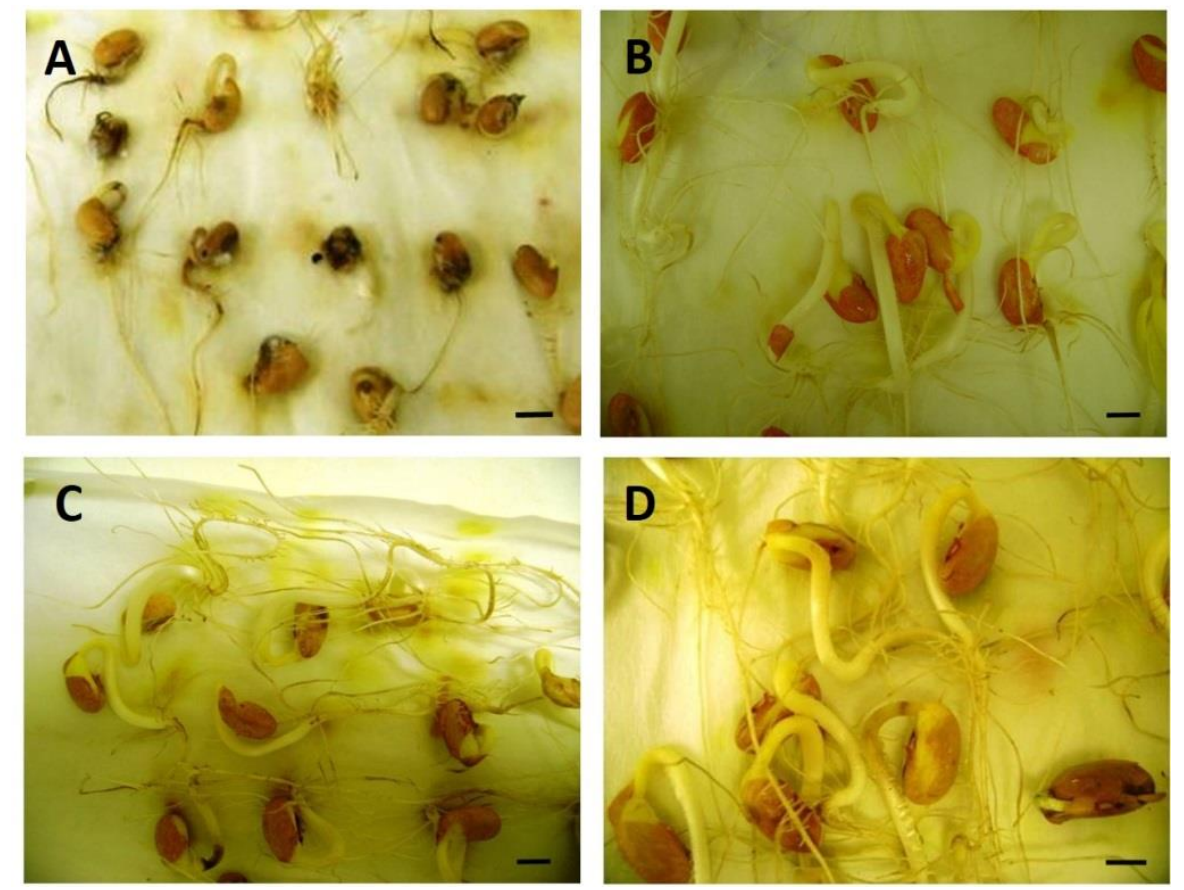

Figura 2 - Plântulas originadas de sementes de feijoeiro 'Jalo Precoce' contaminadas por Sclerotinia sclerotiorum: (A) Após nenhum tratamento, obtenção de sementes mortas e plântulas lesionadas por S. sclerotiorum; (B) Após tratamento com Carboxin+Thiram, obtenção de plântulas normais; (C) Após tratamento com Trichoderma harzianum (CEN287), obtenção de plântulas normais; (D) Após tratamento com T. harzianum (CEN316), obtenção

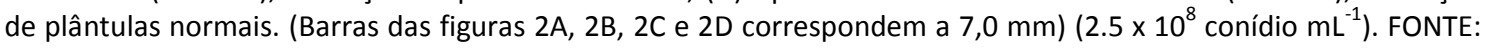
Daniel Diego Costa Carvalho. 
Em se tratando de trabalhos envolvendo aplicação de Trichoderma no campo, pode ser citado o trabalho conduzido por Geraldine et al., (2013), avaliando 10 isolados mediante aplicação foliar no campo. Nesse trabalho, os autores após relacionarem o sucesso obtido no campo com os testes in vitro, conseguiu identificar enzimas (NAGase e $\beta-1,3$-glucanase) e o próprio parasitismo exercido pelo fungo, como componentes-chave durante o processo de controle biológico. Assim, tem-se que os principais objetos de estudo realizados no Brasil em experimentos de campo que podem ser apontados são (1) a seleção de isolados ou avaliação de isolados provenientes de produtos comerciais atualmente disponíveis (Görgen et al., 2009); (2) identificar quais mecanismos de controle estão mais relacionados com o sucesso obtido no campo (Geraldine et al., 2013) e, (3) avaliar o controle biológico juntamente com outras práticas culturais, mensurando-se seus efeitos, dependendo da prática adotada (Paula Júnior et al., 2009).

\section{Trichoderma spp. Como promotores do crescimento de plantas}

Além dos efeitos de Trichoderma spp. no controle de fitopatógenos, certos isolados podem estimular o desenvolvimento de plantas (Harman et al., 2004). Recentemente, a promoção de crescimento do feijoeiro pelo emprego de Trichoderma tem sido objeto de estudo no Brasil (Aguiar et al., 2014; Guimarães et al., 2014). Experimentos conduzidos em casa de vegetação por Pedro et al., (2012), mostraram que isolados de Trichoderma podem proporcionar aumentos superiores a $30 \%$ na produção de matéria seca da parte aérea das plantas de feijão. Já em câmara climatizada, Aguiar et al., (2012) observaram maior altura de plantas de feijoeiro 'Carioca' quando estas foram cultivadas em substrato tratado com $T$. viride. De forma análoga, Carvalho et al., (2011) observaram, em casa de vegetação e campo, maior comprimento médio total de plantas oriunda de sementes e substrato tratado com $T$. harzianum. Adicionalmente, Carvalho et al., (2011) observaram que a promoção do crescimento inicial do feijoeiro está diretamente relacionada com a rizocompetência dos isolados avaliados (Figura 3). Esses efeitos diretos no crescimento das culturas são obtidos porque, além de colonizar a rizosfera das plantas, certos isolados podem produzir substâncias promotoras do crescimento das plantas (Mathivanan et al., 2005), e ainda solubilizar nutrientes da rizosfera, tornando-os disponíveis às raízes (Hoyos-Carvajal et al., 2009).
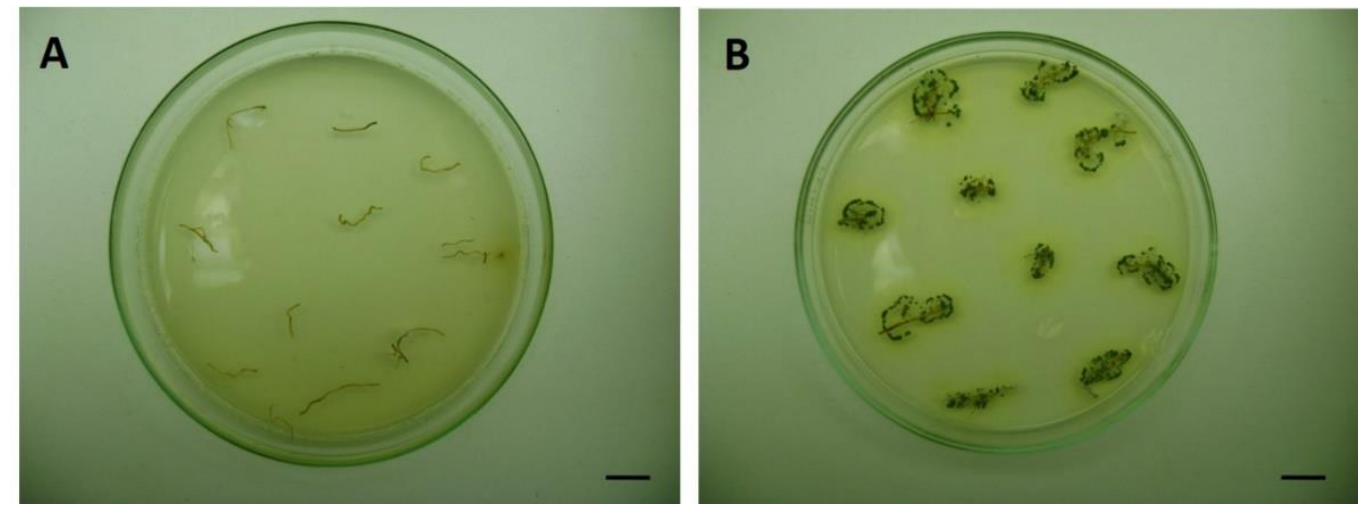

Figura 3 - Rizocompetência de Trichoderma harzinaum em plantas de feijoeiro 'Jalo Precoce'. (A) Fragmentos de raízes oriundos de plantas cultivadas em substrato (areia esterilizada) não tratado com $T$. harzianum; (B) Fragmentos de raízes oriundos de plantas cultivadas em substrato (areia esterilizada) tratado com T. harzianum. (Barras das figuras 3A e 3B correspondem a $10,0 \mathrm{~mm})\left(2.5 \times 10^{8}\right.$ conídio $\left.\mathrm{mL}^{-1}\right)$. FONTE: Daniel Diego Costa Carvalho.

Enfim, a ação de Trichoderma como estimulador do crescimento é complexa e realizada por interações com fatores bioquímicos e produção de diversas enzimas e compostos benéficos (antibiose, promoção de crescimento) (Machado et al., 2012). Desse modo, enquanto o controle biológico de doenças por Trichoderma ser uma linha de pesquisa bastante 
desenvolvida no Brasil, estudos focados na promoção de crescimento do feijoeiro necessitam de avanços.

\section{Considerações finais}

No Brasil estudos importantes têm mostrado o emprego de Trichoderma no controle do mofo branco do feijoeiro, especialmente em condições de campo. Entretanto, a promoção do crescimento de plantas e a patologia de sementes são áreas carentes de estudos de maior impacto.

Por possuir ampla gama de mecanismos de ação, trabalhos de pesquisa realizados no Brasil tem apontado isolados de Trichoderma eficientes no controle de patógenos habitantes do solo e com grandes perspectivas para o desenvolvimento de produtos comerciais mais eficientes do que os atualmente disponíveis.

Notoriamente, a presente revisão apresentou algumas características relacionadas ao fungo Trichoderma no controle de S. sclerotiorum (em condições de campo e em sementes) e Cladosporium (em sementes), bem como, na promoção de crescimento em plantas de modo que, atendendo à demanda mundial, são importantes estudos com microrganismos no controle de doenças, com vistas à redução do uso de produtos químicos no tratamento de sementes para controle do mofo branco, que são práticas tóxicas aos aplicadores e ao meio ambiente.

\section{Agradecimentos}

Os autores agradecem ao apoio oferecido pelo Programa de Bolsa de Incentivo à Pesquisa e Produção Científica (PROBIP) da Universidade Estadual de Goiás (UEG).

\section{Referências}

1. AGÜERO, L. E. M. et al. Inhibition of Aspergillus flavus growth and aflatoxin b1 production in stored maize grains exposed to volatile compounds of Trichoderma harzianum Rifai. Interciência, Caracas, v. 33, n. 3, p. 219-222, 2008.

2. AGUIAR, A. R. et al. Seleção de isolados de Trichoderma spp. na promoção de crescimento de mudas do feijoeiro cv. carioca e controle de Sclerotinia sclerotiorum. Ciência e Natura, Santa Maria, v. 34, n. 2, p. 47-58, 2012.

3. AGUIAR, P. E. V.; BONALDO, S. M.; MORAES, S. R. G. Avaliação de Trichoderma spp. na cultura de feijão, em antracnose, mela e nematoide das galhas. Scientific Electronic Archives, Sinop, v. 7, p. 17- 25, 2014.

4. ALWATHNANI, H. A. et al. Evaluation of biological control potential of locally isolated antagonist fungi against Fusarium oxysporum under in vitro and pot conditions. African Journal of Microbiology Research, Nairobi, v. 6, n. 2, p. 312-319, 2012.

5. ANDREWS, J. H. Strategies for selecting antagonistic microrganisms from the phylloplane. In: WINDELS, C.L.; LINDON, S.E. Biological control on the phylloplane. St. Paul: The American Phytopathological Society, 1985. p. 31-44.

6. BARBOSA, F. R.; GONZAGA, A. C. O. Informações técnicas para o cultivo do feijoeirocomum na Região Central-Brasileira: 2012-2014. Santo Antônio de Goiás: Embrapa Arroz e Feijão, Documentos, 2012. 247 p. 
7. BIANCHINI, A.; MARINGONI, A. C; CARNEIRO, S. M. T. P. G. Doenças do feijoeiro. In: KIMATI, H.; AMORIM, L.; REZENDE, J.A.M.; CAMARGO. (Ed.). Manual de Fitopatologia: Doenças das Plantas Cultivadas. v.2, 4 ed. São Paulo: Agronômica Ceres, 2005. p. 333350 .

8. CARVALHO, D. D. C. et al. Biological control of Fusarium oxysporum f. sp. Phaseoli by Trichoderma harzianum and its use for common bean seed treatment. Tropical Plant Pathology, Viçosa, v. 39, n. 5, p. 384-391, 2014.

9. CARVALHO, D. D. C. et al. Biocontrol of seed pathogens and growth promotion of common bean seedlings by Trichoderma harzianum. Pesquisa Agropecuária Brasileira, Brasília, v. 46, n. 8, p. 822-828, 2011.

10. CONAB. Acompanhamento de safra brasileira: Grãos - Safra 2013-2014. Brasília: Companhia Nacional de Abastecimento. Conab. 2014. 41 p. Disponível em: <http://www.conab.gov.br/con3teudos.php?a=1253\&t/>. Acesso em: 30 mai. 2014.

11. CONSOLO, V. F. et al. Characterization of novel Trichoderma spp. isolates as a search for effective biocontrollers of fungal diseases of economically important crops in Argentina. World Journal of Microbiology and Biotechnology, Dordrecht, v. 28, n. 4, p. 1389-1398, 2012.

12. FERREIRA, S. H. et al. Medicamentos a partir de plantas medicinais no Brasil. Rio de Janeiro: Academia Brasileira de Ciências, 1998. 131 p.

13. FIALHO, M. B. et al. Potential of antimicrobial volatile organic compounds to control Sclerotinia sclerotiorum in bean seeds. Pesquisa Agropecuária Brasileira, Brasília, v. 46, n. 2, p. 137-142, 2011.

14. FRAVEL, D. R. Commercialization and implementation of biocontrol. Annual Review of Phytopathology, Palo Alto, v. 43, p. 337-359, 2005.

15. GERALDINE, A. M. et al. Cell wall-degrading enzymes and parasitism of sclerotia are key factors on field biocontrol of white mold by Trichoderma spp. Biological Control, San Diego, v. 67, n. 3, p. 308-316, 2013.

16. GÖRGEN, C. A. et al. Controle do mofo-branco com palhada e Trichoderma harzianum 1306 em soja. Pesquisa Agropecuária Brasileira, Brasília, v. 44, n. 12, p. 1583-1590, 2009.

17. GUIMARAES, G. R.; CARVALHO, D. D. C. Incidência e caracterização morfológica de Cladosporium herbarum em feijão comum cv. 'Pérola'. Revista Brasileira de Biociências, Porto Alegre, v. 12, n. 3, p. 137-140, 2014.

18. GUIMARÃES, G. R. et al. Supression of seed borne Cladosporium herbarum on common bean seed by Trichoderma harzianum and promotion of seedling development. Tropical Plant Pathology, Viçosa, v. 39, n. 5, p. 401-406, 2014.

19. HARMAN, G. E. Seed treatment for biological control of plant disease. Crop Protection, Oxford, v. 10, p. 166-171, 1991. 
20. HARMAN, G. E. et al. Trichoderma species - opportunistic, avirulent plant symbionts. Nature reviews microbiology. London, v. 2, p. 43-56, 2004.

21. HOYOS-CARVAJAL, L.; ORDUZ, S.; BISSETT, J. Growth stimulation in bean (Phaseolus vulgaris L.) by Trichoderma. Biological Control, San Diego, v. 51, n. 3, p. 409-416, 2009.

22. HUANG, H.C. et al. Foliar Application of Fungal Biocontrol Agents for the Control of White Mold of Dry Bean Caused by Sclerotinia sclerotiorum. Biological Control, San Diego, v. 18, n. 3, p. 270-276, 2000.

23. ITO, M. F. et al. Importância do uso de sementes sadias de feijão e tratamento químico. O Agronômico, Campinas, v. 55, p. 14-16, 2003.

24. KISHORE, G. K.; PANDE, S.; PODILE, A. R. Biological control of collar rot disease with broad-spectrum antifungal bacteria associated with groundnut. Canadian Journal of Microbiology, Ottawa, v. 51, n. 2, p. 123-132, 2005.

25. LOBO JÚNIOR, M.; GERALDINE, A. M.; CARVALHO, D. D. C. Controle biológico de patógenos habitantes do solo com Trichoderma spp., na cultura do feijoeiro comum. Santo Antônio de Goiás: Embrapa Arroz e Feijão, Circular Técnica 85, 2009. 4 p.

26. LOPES, F. A. C. et al. Biochemical and metabolic profiles of Trichoderma strains isolated from common bean crops in the Brazilian cerrado, and potential antagonism against Sclerotinia sclerotiorum. Fungal Biology, Oxford, v. 116, n. 7, p. 815-824, 2012.

27. LOUZADA, G. A. S. et al. Antagonist potential of Trichoderma spp. from distinct agricultural ecosystems against Sclerotinia sclerotiorum and Fusarium solani. Biota Neotropica, Campinas, v. 9, n. 3, p. 145-149, 2009.

28. MACHADO, D. D. F. et al. Trichoderma no Brasil: O fungo e o bioagente. Revista de Ciências Agrárias, Lisboa, v. 35, n. 1, p. 274-288, 2012.

29. MATHIVANAN, N.; PRABAVATHY, V. R.; VIJAYANANDRAJ, V. R. Application of talc formulations of Pseudomonas fluorescens Migula and Trichoderma viride Pers. ex S.F. Gray decrease the sheath blight disease and enhance the plant growth and yield in rice. Journal of Phytopathology, Hoboken, v. 153, n.11-12, p. 697-701, 2005.

30. MELO, I. S.; FAULL, J. L.; NASCIMENTO, R. S. Antagonism of Aspergillus terreus to Sclerotinia sclerotiorum. Brazilian Journal of Microbiology, São Paulo, v. 37, p. 417-419, 2006.

31. MELLO, S. C. M. Doenças causadas por fungos de solo $x$ Trichoderma. Campo \& Negócios, Uberlândia, v. 20, p. 42-47, 2014.

32. MOREIRA, A. C.; ANTUNES, A. M. S.; PEREIRA JÚNIOR, N. Patentes: extratos de plantas e derivados. Biotecnologia Ciência \& Desenvolvimento, Brasília, v. 7, p. 62-71, 2004.

33. PAULA JÚNIOR, T. J. et al. White mold intensity on common bean in response to plant density, irrigation frequency, grass mulching, Trichoderma spp., and fungicide. Summa Phytopathologica, Botucatu, v. 35, n. 1, p. 44-48, 2009. 
34. PEDRO, E. A. S. et al. Promoção do crescimento do feijoeiro e controle da antracnose por Trichoderma spp. Pesquisa Agropecuária Brasileira, Brasília, v. 47, n. 11, p. 1589-1595, 2012.

35. PEREIRA, F. S. et al. Estratégias de controle de mofo branco do feijoeiro. Enciclopédia Biosfera, Goiânia, v. 9, n. 17, p. 1354-1371, 2013.

36. REgRAS PARA ANÁLISE DE SEMENTES. Ministério da Agricultura, Pecuária e Abastecimento. Secretaria de Defesa Agropecuária. - Brasília: Mapa/ACS, 2009. 399 p.

37. ROCHA. R. et al. Selection of endophytic fungi from comfrey (Symphytum officinale L.) for in vitro biological control of the phytopathogen Sclerotinia sclerotiorum (Lib.). Brazilian Journal of Microbiology, São Paulo, v. 40, p. 73-78, 2009.

38. SAITO, L. R. et al. Aspectos dos efeitos do fungo Trichoderma spp. no biocontrole de patógenos de culturas agrícolas. Pesquisa Aplicada \& Agrotecnologia, Guarapuava, v. 2, n. 3, p. 203-208, 2009.

39. WUTZKI, C. R. et al. Reduction of white mold level on soybean by fungicide management strategies. Bioscience Journal. v. 32, n. 3, p. 642-651, 2016.

40. WOOD, R. K. S.; TVEIT, M. Control of plant diseases by use of antagonistic organisms. Botanical Review, New York, v. 21, p. 441-492, 1955.

41. VIDA, J.B., ZAMBOLIM, L., TESSMANN, D.J., BRANDÃO FILHO, J.U.T., VERZIGNASSI, J.R. \& CAIXETA, M.P. Manejo de doenças de plantas em cultivo protegido. Fitopatologia Brasileira v.29, p.355-372, 2004.

42. ZUCCHI, T. D.; MELO, I. S. Controle biológico de fungos aflatoxigênicos. In: BETTIOL, W.; MORANDI, M.A.B. (Ed.). Biocontrole de doenças de plantas: uso e perspectivas. Jaguariúna: Embrapa Meio Ambiente, 2009. p. 69-94. 